\title{
LA INTANGIBILIDAD DE LAS ACCIONES Privadas de las Personas
}

INVIOLABILITY OF PRIVATE ACTIONS OF INDIVIDUALS

\author{
Mauricio Maldonado Muñoz*
}

Resumen: En este artículo pretendemos acercarnos a una garantía que — siguiendo cierta doctrina - hemos llamado: intangibilidad de las acciones privadas de las personas. Desde una visión que busca ser omnicomprensiva, se analizan las fuentes de las que mana la privacidad $\mathrm{y}$, posteriormente, su contenido y alcances. Sobre todo, se analiza el problema de los límites de la injerencia y regulación estatal, partiendo de una posición que niega las visiones comunitaristas. En general, se trata de conceptualizar a la garantía planteada desde el punto de vista de la libertad, el derecho y las virtudes humanas, los derechos de terceros y la moral pública; concretando su vinculación con otros derechos relacionados con la privacidad. La idea central del presente trabajo consiste en demostrar la transversalidad de la garantía señalada, implicando - en ese proceso- cuestiones trascendentes para la filosofía del derecho, la teoría del derecho y, por supuesto, para el estudio del derecho de los derechos humanos.

Palabras clave: Privacidad, intimidad, libertad, derechos de terceros, moral pública

* Licenciado en ciencias jurídicas y abogado por la Pontificia Universidad Católica del Ecuador (Quito). Magíster en Derecho (LL.M.) por la Universidad Austral (Buenos Aires, Argentina). Doctorando (Ph.D.) en Filosofía del Derecho y Bioética Jurídica por la Università degli studi di Genova (Italia). mmaldonadomunoz@gmail.com 
Abstract: This article aims to approach a warranty called: inviolability of private actions of individuals. The right to privacy, in its content and scope, is aboard from a widespread vision. Principally, the issue about the limits of the State interventions and regulations it's analyzed, from a position that denies the theory of communitarianism. In general, this article conceptualize the most important issues about freedom, law and human virtues, rights of others and public morals; concreting this topics with its entailment with other human rights related to the right to privacy. The central idea of this paper is to demonstrate the mainstreaming or transversality of the warranty (inviolability of private actions of individuals), involving transcendental issues for philosophy of law, legal theory and, of course, human rights.

Key words: Privacy, Intimacy, Freedom, Rights of others, Public Morals

Sumario. I. Planteamiento general. II. La privacidad como consecuencia de la libertad humana. III. La privacidad y la ordenación de las virtudes humanas. La afectación a terceros y la moral pública. IV. Privacidad e intimidad humanas. V. El derecho a elegir el propio plan de vida y el libre desarrollo de la personalidad. VI. La libertad religiosa y la objeción de conciencia. VII. Las acciones privadas, la inviolabilidad de domicilio y de correspondencia. VIII. Las acciones privadas de la asociación humana. IX. A modo de conclusión. Referencias.

A Hernán Salgado Pesantes, maestro, amigo y ejemplo de vida ${ }^{l}$

\footnotetext{
${ }^{1}$ Con afecto dedico este ensayo al profesor Salgado Pesantes con ocasión de su retiro formal de la actividad académica.
}

Ius Humani, v. 4 (2014/15), p. 10 

blasfema.

Lenina se escandalizó ante aquella exclamación

— iBernard! —protestó, dolida y asombrada—. ¿Cómo puedes decir esto?

- ¿Cómo puedo decirlo? — repitió Bernard en otro tono, meditabundo- - No, el verdadero problema es: «iPor qué no puedo decirlo?» $\mathrm{O}$, mejor aún, puesto que, en realidad, sé perfectamente por qué, ¿qué sensación experimentaría si pudiera, si fuese libre, si no me hallara esclavizado por mi condicionamiento?

- Pero, Bernard, dices cosas horribles.

- ¿Es que tú no deseas ser libre, Lenina?

- No sé qué quieres decir. Yo soy libre. Libre de divertirme cuanto quiera. Hoy día todo el mundo es feliz.

Bernard rió.

- Sí, «hoy día todo el mundo es feliz». Eso es lo que les decimos a los niños de cinco años. Pero ¿no te gustaría tener la libertad de ser feliz... de otra manera? A tu modo, por ejemplo; no a la manera de todos.

(Aldous Huxley, Un mundo feliz)

\section{Planteamiento general ${ }^{2}$}

El derecho a la privacidad ha sido reconocido por muchas Constituciones nacionales $\mathrm{y}$ ha sido sostenido por variada jurisprudencia. Así también, ha encontrado protección por parte de muchos instrumentos internacionales de derechos humanos, tal es el caso de los artículos 12 de la Declaración Universal de Derechos Humanos, 11.2 de la Convención Americana de Derechos Humanos, 17.1 del Pacto Internacional de Derechos Civiles y Políticos, y 5 de la Declaración Americana de los Derechos y Deberes del Hombre.

En ese contexto, y aunque nos encontramos frente a un derecho de larga data, no deja de ser necesario examinar el lugar que tiene la privacidad de los individuos, sobre todo ante la

${ }^{2}$ Aclaración: En los casos (salvo en los que se indique lo contrario) en que los textos citados no se encontraban ya traducidos al castellano, la traducción ha sido realizada por el autor para los únicos efectos de la publicación de este trabajo. De otro lado, los textos incluidos entre corchetes dentro de una cita corresponden a precisiones o aclaraciones del autor de este ensayo. 
amenaza de arbitrarias intromisiones, o ante la posibilidad de invasiones estatales en ciertas esferas protegidas de estas intrusiones ilegítimas.

Como llegaremos a concluir en este trabajo, cuando una conducta es estrictamente privada, el Estado no puede regularla de modo alguno.

Así, en este ensayo pretendemos acercarnos al tema planteado analizando las fuentes de las que mana la privacidad y, posteriormente, su contenido y alcances. En particular, analizaremos la conexión de nuestro tema de estudio con la libertad humana para luego abordar la cuestión del derecho y las virtudes humanas con relación a la privacidad y a los derechos de terceros. Luego hablaremos de las distinciones y relaciones de la intimidad y la privacidad. Posteriormente iremos concretando nuestro análisis sobre ciertos derechos específicos relacionados con nuestro concepto; a saber, el derecho a elegir el propio plan de vida y el libre desarrollo de la personalidad, la libertad de conciencia, la libertad religiosa y la objeción de conciencia, la inviolabilidad de domicilio y de correspondencia, y el derecho a la privacidad en el caso de las asociaciones. Al final, brevemente, incluiremos un acápite conclusivo. Todo esto nos permitirá defender, desde una perspectiva global, la intangibilidad de las acciones privadas de las personas ${ }^{3}$.

Advertimos, desde ya, que acudiremos a diversa jurisprudencia y doctrina comparada, pues entendemos que tal ejercicio es enriquecedor $\mathrm{y}$, además, porque a nuestro criterio, el estudio de los derechos humanos, reconocidos como universales, merece la pena ser visto desde esta óptica en tanto sea posible. No debe olvidarse, asimismo, que el derecho del que tratamos es tan antiguo como el hombre civilizado y que, en ese sentido, corresponde a su propia naturaleza. Nada hay de extraño entonces en travesear por las diversas experiencias jurídicas.

${ }^{3}$ El término "intangibilidad de las acciones privadas", lo he tomado de la literatura del profesor Fernando Toller.

Ius Humani, v. 4 (2014/15), p. 12 


\section{LA PRIVACIDAD COMO CONSECUENCIA DE LA LIBERTAD HUMANA}

Hemos dicho en otra oportunidad — siguiendo la doctrina de diversos tratadistas y también nuestras propias reflexiones- que son principios jurídicos suprapositivos aquellos que valen aun ante la ausencia de normas ${ }^{4}$, por cuanto están justificados en sí mismos. Estos principios, en consecuencia de lo anterior, se entiende que «son intrínsecamente razonables» (Maldonado Muñoz, 2013, pág. 7).

Obviamente, para aceptar la afirmación antedicha es menester admitir —en primer lugar - la existencia efectiva de estos principios suprapositivos; o, lo que es lo mismo, de al menos una teoría iusnaturalista, o de su idea transversal, que es, conforme lo ha señalado el profesor Massini Correas, aquella que reconoce «la existencia de al menos un principio suprapositivo jurídico, en el que se fundan racionalmente ciertas normas o derechos» $»^{5}$ (1994, pág. 88). En similar contextualización se puede decir que toda teoría iusnaturalista acepta, al menos, la tesis de la no positividad de todo el derecho.

Dentro de estos principios suprapositivos entendemos incluida a la libertad, por cuanto ella encuentra justificación en la misma naturaleza humana, en cuya ausencia el ser humano no puede realizar sus fines, sean individuales o sociales. Esa libertad es a su vez una potestad psicológica, tanto como un derecho de acción, en cuanto supone la posibilidad de ejercitar las propias

${ }^{4}$ En ese sentido ha dicho el profesor Bidart Campos que el hecho de «[q]ue haya normas declarativas de derechos no significa que cuando faltan normas haya ausencia de derechos. Las cláusulas de los derechos no enumerados que muchas constituciones contienen, da prueba de que hay derechos implícitos. $\mathrm{O}$ sea, que en un Estado democrático el sistema de derechos debe operar tanto con normas como sin normas» (2008, pág. 65).

${ }^{5}$ A este respecto, el mismo autor ha dicho que corresponde considerar como tesis iusnaturalista a la siguiente: «existe al menos una norma $-\mathrm{o}$ un principio - jurídico de fuente no meramente positiva» (1994, pág. 89). 
conductas a salvo de injerencias arbitrarias (Burgoa, 2009, pág. $13)$.

El derecho a la libertad es amplio y, en muchos sentidos, éste es —después de la vida - ${ }^{6}$ aquel que permite el ejercicio de los demás derechos. Es más, en varios casos, esos otros derechos no son sino la propia libertad concretizada en uno de los aspectos a que ella se refiere.

En torno a esto, el profesor Barile ha sostenido que «[e]n orden lógico e histórico, la primera de las libertades constitucionales es la libertad de la persona, o sea libertad con relación a las limitaciones de cualquier género, particularmente - pero no solamente- de aquellas impuestas por el Estado» (1984, pág. 111).

La libertad, como lo explica el profesor Bobbio, se puede entender al menos desde dos perspectivas, una tradicional y otra moderna. En la primera hablamos generalmente de libertad como ausencia de impedimentos o libertad negativa. En ese sentido, en una primera acepción, la libertad supone que «[t]odo ser humano debe tener una esfera de actividad personal protegida contra las injerencias de los poderes exteriores, en particular del poder estatal».

De modo posterior, desde el punto de vista conceptual, la libertad se tornó también en autonomía, en tanto supone la adscripción a unas leyes establecidas por las propias personas, no ya solamente a la ausencia de éstas en el sentido tradicional. De esa misma conceptualización de la libertad nació la idea de libertad política «como desarrollo de las libertades civiles, o de la forma democrática de gobierno como desarrollo o integración de la forma pura y originariamente liberal». Una segunda "mutación"

\footnotetext{
${ }^{6}$ En el fallo Bahamondez, la Corte Suprema de Justicia de la Nación argentina dijo: «De este modo, vida y libertad forman la infraestructura sobre la que se fundamenta la prerrogativa constitucional que consagra el artículo 19 de la Constitución Nacional [relativo a las acciones privadas de las personas]». C.S.J.N., Bahamondez, Fallos 316:479, voto de los jueces Fayt y Barra.

Ius Humani, v. 4 (2014/15), p. 14
} 
del concepto se dio paso cuando la idea de libertad negativa se tornó positiva en el sentido de que la libertad debería garantizar, además, la «capacidad jurídica y material para concretar las posibilidades abstractas garantizadas por las constituciones liberales» (2009, pág. 526).

En principio, es de la primera acepción de libertad que nos interesa hablar ${ }^{7}$, aunque también se advertirán implicancias en las demás concepciones ${ }^{8}$ (sobre todo en cuanto a la libertad en tanto autonomía, incluso porque su desambiguación sirve para distinguir dos aspectos de un mismo concepto, pero no dos conceptos diferentes). En ese contexto, nos interesa acercarnos a una conceptualización de la privacidad que reconoce a la libertad como el «poder hacer todo aquello que no perjudique a otro» ${ }^{9}$, la facultad de dictarse las propias ideas y opciones vitales, y a permanecer libre de intrusiones en estos ámbitos.

Está claro - al menos en torno a su entendimiento histórico - que la privacidad como ejercicio de libertad no ha permanecido como una concepción inmutable ${ }^{10}$.

${ }^{7}$ Dice el profesor Bernal Pulido — siguiendo al profesor Berlin — que «debe reivindicarse que el concepto constitucional de libertad no es el de libertad positiva, sino el de libertad negativa. De acuerdo con este último concepto, el individuo no sólo es libre de hacer lo razonable o necesario, sino libre de hacer o dejar de hacer lo que quiera, sin intervenciones externas provenientes del Estado o de otros individuos» (2008, pág. 249).

${ }^{8}$ El propio profesor Bernal Pulido — esta vez siguiendo a Kant — ha dicho que «esta concepción de la libertad jurídica como libertad negativa no elimina la libertad positiva, sino que la reserva para el fuero interno del individuo del individuo, para su órbita como creyente, como sujeto laico o como sujeto ético» (2008, pág. 249).

${ }^{9}$ Conforme se había entendido ya en el art. 4 de la Declaración de los Derechos del Hombre y del Ciudadano (1789), y en cuanto señala el art. 5: «La ley sólo tiene derecho a prohibir los actos perjudiciales para la sociedad».

${ }^{10}$ El profesor Bernal Pulido, ha dicho que «el objeto de la libertad evoluciona con los tiempos, se recrea, cambia, y por ello se escurre a las previsiones de todo poder constituyente, por más visionario y garantista que éste pueda ser» (2008, pág. 250). 
Al contrario, se puede señalar — como lo han hecho los profesores Warren y Brandeis - que en la tradición del common law, en tiempos muy tempranos, la ley «dio remedios solamente contra interferencias físicas en la vida o la propiedad mediante intrusiones por la fuerza y las armas»; aunque, de modo posterior se buscara salvaguardar también la entidad y naturaleza no meramente física de los sentimientos humanos. A este respecto, los profesores citados han sostenido que «la intensa vida intelectual y emocional, y el crecimiento de las sensaciones que llegaron con el avance de la civilización, han dejado claro que solamente una parte del miedo, del placer o de lo beneficioso de la vida recaen en aspectos físicos. Los pensamientos, las emociones y las sensaciones demandan reconocimiento legal [y son parte de la esfera privada del individuo]» (1890, pág. 195).

Esta concepción que hemos indicado se acerca a una postura que, en principio, podemos considerar liberal y, más precisamente en la contextualización presentada, propia de un humanismo laico (secular), donde los derechos - como dice el profesor Zagrebelsky - son «hijos de la tradición antiescolástica que se inició con la fractura operada por el espíritu del renacimiento (...) Esa consiste en la visión individual de la propia existencia, una visión de la que deriva la pretensión de poder actuar en conformidad con ella» (2011, págs. 79-80).

Ahora, si bien es cierto que la tradición moderna del estudio de los derechos humanos reconoce una primera "superación" del paradigma liberal para internarse en una visión social, comúnmente ubicada en la etapa de posguerra, no es menos cierto que la tradición democrática ha conservado indemne una esfera individual importante y que aspira a dejar a salvo de injerencias arbitrarias estos aspectos. Esta visión no se explica de manera idónea, ni sería deseable que ello ocurra, desde las visiones colectivistas. Es en este sector, sobre todo, donde la visión clásica de la libertad posee fuertes implicaciones, de modo que no es incorrecto buscar la mejor explicación ideológica de la privacidad 
(como derecho de libertad), en el liberalismo, sea clásico ${ }^{11} \mathrm{o}$ - en un contexto contemporáneo- deontológico ${ }^{12}$. Aunque, de todos modos, podríamos hablar de "liberalismo", cualquiera a que se refiera, a sola condición de compartir el hecho de que la idea transversal de toda perspectiva liberal supone la imposibilidad de dañar a terceros como límite al derecho y, por supuesto y sobre todo, al Estado. (Esta última descripción no debe tenerse, por cierto, como opuesta al desarrollo del derecho de los derechos humanos, sobre todo en cuanto a los que no se consideran propiamente derechos de libertad, sobre la base de que estos mismos razonamientos sirvan para cada uno de esos casos. Estas consideraciones suponen, solamente, que en cuanto a lo que la libertad privada contiene, su mejor entendimiento nace de la concepción liberal (o, en todo caso, del humanismo secular) y no de la concepción social de los derechos fundamentales. Esto no implica que una "moderna" interpretación no pueda entrañar una vinculación de la libertad en función también de otros derechos con los que debe convivir (por algo habíamos dicho que si bien la privacidad vale sobre todo en la acepción primera de la libertad,

${ }^{11}$ En cuanto a este punto, véanse las argumentaciones del profesor Gabriel Zanotti (Véase: Zanotti, 2006).

${ }^{12} \mathrm{El}$ profesor Massini Correas ha especificado que «para estos autores liberales - que conforman el liberalismo deontológico - normas morales pueden ser únicamente las que cada individuo crea o acepta para sí mismo, basado en sus personales opciones acerca de cómo ha de vivir y de cuáles son sus bienes propios. Más allá de las opciones del sujeto, no existen bienes morales ni modos de vida éticamente mejores que otros (...) [S]ólo resultan justificadas aquellas normas jurídicas que prohíben conductas que causan daño a otros, o que al menos crean el marco normativo necesario para que cada sujeto autónomo realice en la mayor medida posible su "su plan de vida" (...) [C]ada individuo tiene un derecho moral a realizar autónomamente su propio "proyecto vital" y, en el caso de que ese derecho colisione con un objetivo general agregativo el derecho individual ha de "triunfar" necesariamente sobre el interés colectivo, ya que la única justificación de las políticas del Estado radica precisamente en la salvaguarda o promoción de los derechos individuales» (t. 170, pág. 888). 
que ella no puede disociarse, o que encuentra implicancias, también en las demás concepciones del concepto libertad). No obstante, una interpretación del principio de privacidad ha de ajustar, en último término, esos cánones a la letra de la acepción primera de la libertad en un contexto de integralidad y armonización de derechos ${ }^{13}$; lo que no quiere decir, por supuesto, que el concepto primero haya perdido vigencia o que pueda sacrificarse a la privacidad por otros derechos; mucho más cuando, como dice el profesor Bernal Pulido, «uno de los pilares del Estado constitucional y democrático de derecho consiste en reconocer a cada individuo un ámbito de libertad que le es inherente» (2008, pág. 247)).

En el sentido explicado, la privacidad es una consecuencia de la libertad que veda de intromisiones por parte, sobre todo, del Estado. Eso mismo ha entendido cierta jurisprudencia.

Lo ha sostenido, por ejemplo, la Corte Suprema de los Estados Unidos en el caso Griswold vs. Connecticut, donde dijo:

«La Primera Enmienda tiene una penumbra ${ }^{14}$ donde la privacidad está protegida de la intrusión gubernamental» $(1965)^{15}$.

${ }^{13}$ Hemos señalado en otra oportunidad — siguiendo la doctrina de Toller y Serna- que contrariamente a la creencia generalizada, no existen verdaderos conflictos derechos, porque eso vulnera en sí un principio lógico (verdadero y evidente en sí mismo); esto es, el principio de no contradicción en virtud del que no se puede ser y no ser a la vez y en el mismo sentido (dos afirmaciones contrarias no pueden ser, ambas, a la vez, verdaderas). En ese orden de cosas, los conflictos ocurren solamente entre pretensiones o intereses. El anticonflictivismo sugiere, en ese sentido, que los límites de los derechos son internos y que el mejor método no debe jerarquizar o ponderar, sino armonizar (Véase: Maldonado Muñoz, 2013, págs. 11-16).

${ }^{14}$ En principio, cuando la Corte usa el vocablo "penumbra" se refiere a otros derechos no establecidos expresamente por una enmienda, pero que devienen de otros que sí están reconocidos. En una interpretación, estos otros derechos son llamados "derechos periféricos".

${ }^{15}$ De la traducción del profesor Fernando Toller (2008).

Ius Humani, v. 4 (2014/15), p. 18 
Podríamos decir que en similar sentido (pero ampliando el concepto), en el ámbito interamericano, la Corte Interamericana de Derechos Humanos, en el caso Tristán Donoso vs. Panamá, ha sostenido:

«[E]l ámbito de la privacidad se caracteriza por quedar exento e inmune a las invasiones o agresiones abusivas o arbitrarias por parte de terceros o de la autoridad pública» (2009).

Así pues, primero que todo, el derecho a la privacidad se refiere a la persona en sí misma y está estrechamente relacionado con la autodeterminación propia del ser humano. Merece la pena recordar, en torno a esto, la ya clásica concepción plasmada por el juez Cooley, donde la privacidad se conceptúa como el derecho a ser dejado solo: «the right to be let alone» ${ }^{16}$.

Estas definiciones a las cuales nos hemos acercado brindan un contexto en que la libertad se erige como un valor trascendente en la vida humana, que permite a las personas ejercer sus propias visiones. Eso supone la idea de una igual libertad como principio. Nótese que las clásicas declaraciones de derechos usaban también el recurso a la igualdad conjuntamente con la libertad. Así, verbigracia, la Declaración de Derechos de Virginia (1776) señala «que todos los hombres son por naturaleza igualmente libres». A su turno, el artículo 1 de la Declaración de los Derechos del Hombre y del Ciudadano (1789) dice que «todos los hombres nacen y permanecen libres e iguales en derechos». Incluso la Declaración Universal de los Derechos Humanos (1948), ya no clásica sino moderna, acude en parte a esta fórmula cuando dice en su primer artículo que «todos los seres humanos nacen libres e iguales en dignidad y derechos».

Es cierto que estos conceptos - como dice el profesor Bobbio- no significan hoy lo mismo que en las declaraciones

\footnotetext{
16 Véase: Corral Talciani, 2000, pág. 51. En el mismo sentido, véase la disidencia del juez Brandeis en el caso: Olmstead vs. United States, 277 U.S. 438 (1928).
} 
clásicas citadas, como tampoco en las ideas lockeanas, pues su contenido se ha enriquecido; ello no es oponible, sin embargo, a la idea de igual libertad en cuanto a lo que nosotros estamos tratando de conceptualizar como esfera privada de la persona humana. De hecho, el mismo profesor turinés ha reconocido que «ningún conflicto existe, pues, en la Declaración ${ }^{17}$ allí donde la frase "todos los seres humanos nacen libres e iguales" equivale a "todos los seres humanos nacen igualmente libres" o "todos los seres humanos nacen iguales en libertad", en el doble sentido de la expresión: "los seres humanos tienen el mismo derecho a la libertad" y "los seres humanos tienen derecho a una libertad igual"» (2009, pág. 533).

Sobre todo, como se dijo, la distinción en torno a los contenidos modernos de los derechos citados, si bien importa, permanece invariable en lo que atañe a la primera acepción de libertad, por cuanto tal valor corresponde a todas las personas siempre que no provoquen daños a terceros. En tal esfera las personas tienen derecho a no ser molestadas, lo que siempre supone la existencia de límites a la acción estatal; así, dice Rubenfeld que «[p]ara todos los efectos, el derecho a la privacidad tiene todo que ver con el delineamiento de los límites legítimos del poder gubernamental» (1989, pág. 737). Compartimos esta idea.

Otro rasgo importante de estos principios puede ilustrarse desde el contexto del liberalismo deontológico, donde obviamente obra el principio de igual libertad, que conlleva - dice el profesor Migliore - «la idea de un Estado no perfeccionista»; siendo que perfeccionista «es aquella comunidad que tiene un ideal de excelencia humana, y que en función de alcanzar este fin proyecta sus instituciones» (2003, pág. 7). El perfeccionismo, en este estado de cosas, se opone $-\mathrm{e}$ incluso puede resultar inconveniente - al libre desarrollo personal. Al contrario, el liberalismo que hemos venido recogiendo supone que la libertad y

\footnotetext{
${ }^{17}$ Hace referencia a la Declaración Universal de los Derechos Humanos (1948). Ius Humani, v. 4 (2014/15), p. 20
} 
la privacidad implican la potestad de elegir el propio proyecto o plan vital (Migliore, 2003, pág. 6) ${ }^{18}$.

A manera de síntesis, en cuanto a lo que se ha explicado, entendemos que la privacidad es una consecuencia de la libertad, que supone una esfera de no injerencia externa, sobre todo estatal, que protege la elección del propio plan vital (con todas sus implicaciones) y que se refiere, en último término, a toda acción propiamente privada que no afecta a terceros.

En cuanto a esto último, el profesor Nino dice que la privacidad - diferenciada en sentido estricto del concepto intimidad $^{19}$ - engloba «a las acciones voluntarias de los individuos que no afectan a terceros. Estas acciones son "privadas" no en el sentido de que no son o no deben ser accesibles al conocimiento público sino en el sentido de que si violentan exigencias morales sólo lo hacen con las que derivan de ideales de una moral privada, personal o autorreferente» (2005, pág. 305).

La intangibilidad de las acciones privadas, en el sentido descrito en este trabajo, supone la existencia de una esfera de libertad indisponible y reservada, asignada sólo al individuo - a su familia o a otros núcleos asociativos humanos - para que en ella pueda desarrollarse y desenvolverse autónomamente según sus propias convicciones y sin injerencia externa de cualquier especie. Así concebido, el derecho a la privacidad no implica solamente la ausencia de coacción estatal o la inmunidad al derecho sancionador, sino que «puede y debe ir más allá, configurando un estricto derecho a la intangibilidad de las acciones y de la vida privada personal y familiar, que quedan también fuera de la indebida intromisión obligatoria de las actividades de policía, de salubridad y de fomento administrativo» (Toller \& De Reina Tartiére, 2002, pág. 10).

\footnotetext{
${ }^{18}$ Con relación al pensamiento de John Rawls.

${ }^{19}$ En otro acápite será tratada esta cuestión.
} 
Esto que hemos señalado puede encontrar parangón con lo que la Corte Constitucional italiana, en la sentencia 366/1991, ha descrito así:

«La Constitución reconoce un valor particular a la intangibilidad de la esfera privada en los aspectos más significativos y más allegados a la vida íntima de la persona humana» (1991).

\section{LA PRIVACIDAD Y LA ORDENACIÓN DE LAS VIRTUDES HUMANAS. LA AFECTACIÓN A TERCEROS Y LA MORAL PÚBLICA}

Hasta ahora hemos hablado desde una visión liberal (habíamos dicho también: humanista secular) y hemos entendido que esa contextualización delinea de manera idónea a la privacidad. Empero, nos parece importante destacar también una visión más antigua, pero no menos interesante en torno a la esfera de regulación del derecho; esto es, la postura tomista, en la que se ha abordado la cuestión sobre la ley humana en el sentido de que no puede ordenarse a todas las virtudes (pues eso mismo sería ajeno a su cometido). Piensa el Aquinate que el derecho está encaminado solamente a buscar lo bueno para la comunidad (lo bueno comunitario). En torno a esto, ha dicho que «la ley humana no legisla acerca de todos los actos de todas las virtudes, sino solamente de los que son ordenables al bien común» (De Aquino, cuestión 96, art. 3).

El profesor Massini Correas recoge esta visión de Santo Tomás, para luego indicar que el mismo Aquinate había señalado que la ley humana no prohíbe todos los vicios, «sino solamente los más graves, aquéllos que la mayor parte de la multitud puede evitar $\mathrm{y}$, sobre todo, los que van en perjuicio de los demás, sin 
cuya prohibición la sociedad humana no podría sostenerse» (Massini Correas, E.D. t. 170, pág. 890) ${ }^{20}$.

En lo que importa a este estudio, entendemos que tanto la visión tomista como la liberal coinciden en señalar que la ley humana no puede legislar sino sobre lo que afecta a terceras personas. En consecuencia, ciertos actos humanos quedan naturalmente fuera de la esfera de control del derecho, que sólo debe buscar el bien común político sin afectar a los derechos individuales ${ }^{21}$. No obstante $-\mathrm{y}$ el profesor Massini Correas lo advierte - el liberalismo, al ser una visión que rebasa al derecho, no sostiene esta idea sobre la base de algún bien humano, menos uno común. Ocurre lo contrario con el iusnaturalismo. No debe olvidarse, sin embargo, que en tanto que el liberalismo representa la oposición al Estado absoluto, necesita del iusnaturalismo como presupuesto filosófico (Bobbio, 1985, págs. 9-11). Se diría pues que constituye este presupuesto en la medida en que sostiene que existen ciertos derechos anteriores a la formación de la comunidad política y que, por ende, no son otorgados por ella, sino que le corresponden a la persona. Por lo tanto, téngase en cuenta que en función histórica el Estado liberal se opone a un Estado máximo, defendiendo un Estado mínimo (antagónico naturalmente del

\footnotetext{
${ }^{20}$ Con relación a la cuestión 100 , art. 2

${ }^{21}$ Sobre el concepto de 'bien común' en el ámbito interamericano, la Corte Interamericana de Derechos Humanos ha señalado lo siguiente: «No escapa a la Corte... la dificultad de precisar de modo unívoco los conceptos de 'orden público' y 'bien común', ni que ambos conceptos pueden ser usados tanto para afirmar los derechos de la persona frente al poder público, como para justificar limitaciones a esos derechos en nombre de los intereses colectivos. A este respecto debe subrayarse que de ninguna manera podrían invocarse el 'orden público' o el 'bien común' como medios para suprimir un derecho... Esos conceptos en cuanto se invoquen como fundamento de limitaciones a los derechos humanos, deben ser objeto de una interpretación estrictamente ceñida a las 'justas exigencias' de 'una sociedad democrática' que tenga en cuenta el equilibrio entre los distintos intereses en juego y la necesidad de preservar el objeto y fin de la Convención» (Opinión Consultiva 5/86, Corte IDH).
} 
Estado absoluto), y que, en función dogmática, trajo al derecho constitucional clásico la idea de la inherencia de derechos.

Retomando la visión tomista, diremos que esta entiende que, en último término, el derecho tiende a inducir a la virtud a las personas y que, por ende, no existe una neutralidad moral del derecho. Liberalismo y tomismo diferirían, en esta parte, en cuanto el liberalismo no considera esta idea y, salvo el daño a terceros, no hay "moralidades" mejores que otras.

En realidad, si aceptamos que la ley humana no legisla $-\mathrm{O}$ no debe legislar - sobre los actos que no afectan a terceros, deberemos entender a su vez que existe, al menos, una mínima moralidad del derecho; ésta es: el respeto a los derechos de los demás. Esto nos lleva a afirmar que la moral es fuente de derecho sólo en cuanto se refiere a derechos, pero no respecto de otros ámbitos referidos generalmente al fuero interno del ser humano.

En otras visiones, sosteniendo esta vinculación moralderecho, se ha dicho que tal tendría sentido ya que sostener lo contrario implicaría aceptar la posible existencia de regímenes jurídicos predatorios o imposibles, y con el argumento de la pretensión de corrección (Véase, a más precisiones: Alexy, 2003, págs. 157-159). La idea de conexión está presente, asimismo, en Dworkin o Zagrebelsky, al menos en torno a los sistemas jurídicos constitucionales contemporáneos (Véase: Comanducci, 2002, pág. $\left.100^{22}\right)$.

22 No obstante haber recurrido a citar al profesor Comanducci, téngase en cuenta que en el ensayo del que hablamos el profesor ha realizado una crítica a ciertas visiones neo-constitucionalistas. En este campo en específico, ha dicho: «Dado que algunos de sus promotores (pienso por ejemplo en Alexy, Dworkin o Zagrebelsky) entienden que, en los ordenamientos democráticos y constitucionalizados contemporáneos, se produce una conexión necesaria entre derecho y moral, el neoconstitucionalismo ideológico se muestra proclive a entender que puede subsistir hoy una obligación moral de obedecer a la Constitución y a las leyes que son conformes a la Constitución. Y en este específico sentido, el neoconstitucionalismo puede ser considerado como una moderna variante del positivismo ideológico del siglo XIX, que predicaba la Ius Humani, v. 4 (2014/15), p. 24 
Veníamos diciendo que los límites de la privacidad —que se delinean internamente- se expresan externamente en una barrera constituida por los derechos de terceros y, en último término, por la moral pública, en la que entendemos incluidos ciertos aspectos necesarios para una normal convivencia social. En efecto, el derecho a la privacidad admite regulaciones que, como en todos los casos, deben ser razonables (Maldonado Muñoz, 2013, págs. 16-17). Vale aclararlo, regulaciones no significan restricciones. Por supuesto, esto lo decimos tratando de cuidar un lenguaje jurídico más preciso en el que los derechos, que por definición constituyen límites al poder, no pueden ser - en sentido estrictotambién limitados por el mismo poder, sino tan solamente reglamentados; o, lo que es lo mismo, que ningún derecho puede ser sacrificado. Digamos, por abundar, que nosotros consideramos derechos sólo a aquellos que pueden tener esta entidad jurídica desde el punto de vista interno, o sea rechazando lo mismo la idea del contenido esencial en sentido absoluto, que en sentido relativo; optando siempre por una tercera vía que delinea los derechos, no desde la confrontación, sino desde los límites de la razonabilidad (Maldonado Muñoz, 2013, págs. 150-156 \& 163166).

Ayudándonos de este breve digresión, diremos que el ámbito reservado que supone la esfera privada posee limitaciones intrínsecas ${ }^{23}$ fuera de las cuales no puede extenderse sin violentar otros preceptos.

En ese sentido se ha pronunciado la Corte Constitucional italiana en la sentencia 121/1963, donde señaló:

«Aquella esfera de privacidad debe ser respetada dentro de los límites que consienta la tutela de los intereses de la colectividad en el

obligación moral de obedecer la ley» (2002, pág. 100). No nos referiremos ahora a la apreciación del profesor Comanducci, sólo nos interesa dejar sentado su criterio específico sobre esta cuestión, para evitar confusiones.

${ }^{23}$ Constituyendo estas limitaciones: los derechos de terceros y la moral pública. 
campo de la seguridad, de la economía y de las finanzas públicas» (1963).

Algo similar dijo la Corte Suprema de Justicia de la Nación argentina, en el caso Ponzetti de Balbín c/ Editorial Atlántida, así:

«Sólo por ley podrá justificarse la intromisión, siempre que medie un interés superior en resguardo de la libertad de los otros, la defensa de la sociedad, las buenas costumbres o la persecución del crimen» (1984).

Entendemos, por lo que aquí se ha expresado, que la intangibilidad de las acciones privadas supone la imposibilidad de adentrarse en estas conductas siempre que no resulten lesivas de derechos de terceros, y que las "excepciones" señaladas en los fallos citados pueden ser aplicadas solo en cuanto no constituyan la violación del derecho a la privacidad (nuevamente sobre la armonización de derechos).

Ahora bien, sobre los límites (nosotros diríamos: internos) del derecho, compartimos la opinión del profesor Nino en cuanto señala que las así llamadas "afectaciones a terceros" no deben ser meramente subjetivas, y que además deben ser relevantes y sustanciales. El profesor piensa, en ese orden de cosas, que al menos existen cuatro casos en que los "daños a terceros" no pueden servir de justificación para interferir en la autonomía del individuo, así: «a) el que es insignificante comparado con la centralidad que tiene la acción para el plan de vida del agente; b) el que se produce no directamente por la acción en cuestión, sino por la interposición de otra acción voluntaria; c) el que se produce gracias a la intolerancia del dañado; y, d) el que se produce por la propia interferencia del Estado» (2005, pág. 307).

Visto esto que antecede, se pueden ejemplificar ciertas conductas que el derecho generalmente pena, pero que no afectan a terceras personas o a la moral pública, así la prohibición de practicar ciertos deportes peligrosos o de circular sin casco en una 
motocicleta ${ }^{24}$. Entendemos que estas conductas no deberían penarse o prohibirse en base a los principios aquí descritos.

No compartimos las ideas del profesor Nino, en cambio, en lo que respecta a la ausencia de daños a terceros en el aborto. El profesor argentino considera que «el feto en su primer período de gestación no tiene los atributos que permiten ser destinatario de derechos ni satisface exigencias para predicar su identidad con alguien que los tendrá en el futuro» (2005, pág. 309).

Nos parece, sin embargo, que la discusión no se basa en las consideraciones que hacen que, de modo general, apreciemos la vida humana en cuanto está llena de ciertas aptitudes. Eso mismo implicaría que estratifiquemos la vida conforme a distinciones basadas en las capacidades humanas (con los peligros que eso acarrearía). Por el contrario, «la autodeterminación, si bien es un indicio del estatuto sui generis de la persona, no es el criterio para delimitar quiénes tienen dignidad y quiénes no la tienen» (Pacheco Zerga, 2007, pág. 47). Realizar distinciones con esta base no sería posible ni deseable desde la óptica de los derechos fundamentales, menos aún respecto de la vida.

Más bien, la discusión al respecto pasa por entender si podemos considerar al nasciturus como "un tercero" al que estaríamos afectando. Así bien, la calidad de tercero se da, en cuanto a los seres humanos, cuando entendemos que existe vida ${ }^{25}$. Consideramos, asimismo, que en principio la vida es inviolable.

${ }^{24}$ En el caso People vs. Fries la Corte Suprema de los Estados Unidos anuló una ley que obligaba a las personas a usar cascos cuando conducían motocicletas (Al respecto, véase: Nino, 2005, pág. 315).

${ }^{25}$ Es notable como puede identificarse un ser tercero, diferente de la madre y el padre, desde el momento de la singamia, cuando el código genético que individuará a ese ser humano queda registrado. Dicho código acompañará siempre al individuo, no obstante sus cambios naturales provocados por el crecimiento o, posteriormente, el envejecimiento, y no obstante los posibles cambios naturales o accidentales como la pérdida de ciertas capacidades físicas o intelectuales. Bajo esa concepción cada persona es única y, por ende, respecto de otros, un tercero moral y jurídico. 
Deberemos aceptar, por lo tanto, que la privacidad no habilita para cometer aborto $^{26}$, pues el aborto no se refiere a la disposición del propio cuerpo y de la propia vida, que pueden estar cubiertas por una ideología liberal e, incluso, por el derecho. No ocurre lo mismo con la vida de terceros, que puede ser violentada solamente cuando se trata de derechos defensivos de la propia vida, pero que no debe basarse en consideraciones arbitrarias ${ }^{27}$.

Por último, consideramos, como en la propia visión del Aquinate, que cierta moral pública puede ser exigible jurídicamente en la medida en que resulte razonable (referida a la recta razón) y en tanto no violente a la persona en su ser íntimo. Por supuesto, para nosotros, estas exigencias sociales razonables se refieren solamente a las que se derivan de las que impone una normal convivencia social, pero no pueden alcanzar como para que la sociedad constriña al individuo a aceptar ideas o proyectos de vida en cuanto no afecten a terceros. En esa medida, la moral pública es exigible, pero no puede interpretarse disociándola del concepto "no afectación a terceros". Una y otra deben convivir. Negar aquello podría acercarnos peligrosamente a visiones comunitaristas, lo que en último término implicaría la negación de la inherencia de derechos y de la propiedad moral de cada ser humano para buscar sus objetivos de vida según sus propias convicciones. No compartimos, por tanto, la postura del comunitarismo; y nos parece que la tradición liberal y democrática tampoco lo hace.

\footnotetext{
${ }^{26}$ Es por eso que estimamos que las consideraciones del fallo Roe vs. Wade de la Corte Suprema de los Estados Unidos, son erradas.

27 Véase: Maldonado Muñoz, Mauricio, Algunas consideraciones acerca del aborto, artículo de opinión, La República (Ecuador), 09 de julio de 2012; y, Maldonado Muñoz, Mauricio, Aborto no punible en casos de violación, artículo de opinión, La República (Ecuador), 25 de marzo de 2013.
}

Ius Humani, v. 4 (2014/15), p. 28 


\section{PRIVACIDAd E INTIMIDAd hUMANAS}

Algunos autores, el profesor Nino entre ellos, diferencian a la privacidad de la intimidad. En ese orden, la intimidad debe entenderse como «una esfera de la persona que está exenta del conocimiento generalizado por parte de los demás». La privacidad, a su turno, se refiere a «la posibilidad irrestricta de realizar acciones "privadas", o sea acciones que no dañan a terceros» (2005, pág. 327). Otros autores, como el profesor Bidart Campos, usan los términos de modo indistinto (2008, pág. 73).

No obstante, esta distinción tiene sentido, al menos desde el uso común y generalizado de nuestra lengua, puesto que el propio Diccionario de la Real Academia de la Lengua Española hace una diferenciación similar; así, se define "privacidad" como el «ámbito de la vida privada que se tiene derecho a proteger de cualquier intromisión». Mientras, el concepto 'intimidad', en su acepción segunda - que es la que interesa a este estudio- se define como la «zona espiritual íntima y reservada de una persona o de un grupo, especialmente de una familia».

La intimidad, en en ese orden de cosas, se diferencia de la privacidad porque la primera se refiere a una esfera estrictamente reservada del conocimiento público. La segunda, en cambio, no se refiere a un ámbito estrictamente reservado, o si lo hace, se entiende que comprende un sector libre de intrusiones mientras no produzca daños a terceros, aunque este se realice en forma pública.

Entendemos, sin embargo, que la garantía de la que hablamos en este trabajo, o sea la que se refiere a la intangibilidad de las acciones privadas de las personas, es aplicable lo mismo a la intimidad que a la privacidad, de modo que si bien la distinción tiene implicaciones doctrinarias, esas no existen $-\mathrm{O}$ no son relevantes - a efectos de distinguir la garantía. En efecto, la «zona espiritual íntima», como el «ámbito de la vida privada», están vedadas de intromisiones de terceros, sobre todo del Estado. Más aún, las dos, en último término, no son dos estados 
diferentes, sino dos aspectos del mismo estado; es decir, de un ejercicio de individualidad interiorizada o exteriorizada que se realiza en virtud de uno mismo y sin afectar a otras personas o a la moral pública.

Cierta jurisprudencia ha reconocido que cubiertos por la privacidad se encuentran los dos ámbitos que hemos mencionado; así por ejemplo, en el antes citado fallo Ponzetti de Balbín c/ Editorial Atlántida, la Corte Suprema de Justicia de la Nación argentina, dijo:

«En rigor, el derecho a la privacidad comprende no sólo la esfera doméstica, el círculo familiar y de amistad, sino a otros aspectos de la personalidad espiritual o física de las personas tales como la integridad corporal o la imagen y nadie puede inmiscuirse en la vida privada de una persona ni violar áreas de actividad no destinadas a ser difundidas, sin su consentimiento o el de sus familiares autorizados» (1984).

Ya antes habíamos citado a los profesores Warren y Brandeis, que habían dedicado uno de sus trabajos al derecho a la privacidad. Allí señalaron algo que ahora recogemos y que indica lo que hemos contextualizado en este acápite: que la esfera que entendemos privada, se refiere a una privacidad interna y a una externa; privacidad en tanto intimidad y privacidad en torno a las acciones no lesivas de terceros.

La privacidad, como género, se refiere a ambas y aspira a comprender tres aspectos del ser humano: uno espiritual, uno material y otro social. En todos es posible identificar una esfera que el individuo tiene el derecho a conservar indemne ${ }^{28}$.

En todo caso, de esta distinción se siguen ciertos derechos específicos, como el derecho a guardar reserva sobre la información personal, reconocido - en el caso ecuatoriano- por

\footnotetext{
${ }^{28}$ En el caso Olmstead vs. United States, el juez Brandeis, recogiendo lo que había trabajado previamente, dijo que existía esta dimensión espiritual humana, además de un contexto material, que conferían contra el gobierno «el derecho a ser dejado solo», siguiendo la doctrina del juez Cooley (Véase: Olmstead vs. United States, 277 U.S. 438 [1928]).
}

Ius Humani, v. 4 (2014/15), p. 30 
la Constitución, en el artículo 66 núm. 19 y, directamente protegiendo la intimidad personal y familiar, el núm. 20 del mismo artículo.

\section{EL DERECHO A ELEGIR EL PROPIO PLAN DE VIDA Y EL LIBRE DESARROLLO DE LA PERSONALIDAD}

Ya habíamos dicho antes que la esfera de privacidad supone la potestad irrenunciable de elegir el propio plan de vida y la manera de ejecutarlo. Esto dice relación, en primer lugar, con la facultad de formarse el propio pensamiento. Así lo sostuvo la Corte Suprema de los Estados Unidos en el caso Wooley vs. Maynard, donde señaló:

«[Hay] una esfera del intelecto y del espíritu que el Estado no puede tratar de dominar» (1977).

Esta facultad es la que doctrinariamente se ha establecido no sólo como una justificación de la privacidad, sino de la propia libertad humana; particularmente - y como lo ha señalado el juez Anthony M. Kennedy - como una de las justificaciones de la libertad de expresión (relacionada con el desarrollo de la personalidad).

De ese modo, se protege a dicha expresión «porque es elemento esencial de la personalidad humana. Lo que expresamos y cómo lo expresamos define, al menos en la superficie, nuestra identidad, nuestra comprensión de nosotros mismos, nuestra misma existencia» (Kennedy, 1993). Podría decirse, en este sentido, que existe una relación manifiesta entre la libertad de expresión y la autonomía moral de las personas. O sea que estamos hablando de cuestiones necesariamente relacionadas.

Pero estas facultades no son solamente pretensiones de la libertad, sino que están atadas a otros valores, la dignidad por ejemplo. Así pues, ha dicho el profesor Taylor que «la dignidad 
humana consiste en gran parte en la autonomía, es decir, en la capacidad de cada quien para determinar por sí mismo su idea de la vida buena» (Taylor, 1993, pág. 86) ${ }^{29}$.

Esto, que en principio es un atributo del pensamiento, puede exteriorizarse en cuanto la persona puede decidir sobre sí misma y sobre su proyecto vital y, además, ejecutarlo. Justamente en favor de esta facultad se ha pronunciado la Corte Suprema de Justicia de la Nación argentina en la causa Bazterrica,${ }^{30}$, donde dijo:

«[L]a prohibición constitucional de interferir con las conductas privadas de los hombres (...) responde a una concepción según la cual el Estado no debe imponer ideales de vida a los individuos, sino ofrecerles libertad para que ellos elijan» (1986).

En el mismo sentido, la propia Corte Suprema argentina, en el caso Gramajo, entendió lo siguiente:

«En un Estado, que se proclama de derecho y tiene como premisa el principio republicano de gobierno, la Constitución no puede admitir que el propio Estado se arrogue la potestad — sobrehumana - de juzgar la existencia misma de la persona, su proyecto de vida y la realización del mismo, sin que importe a través de qué mecanismo pretenda hacerlo» (2006).

Similar cosa señaló la Corte Interamericana de Derechos Humanos en el caso Ximenes Lopes vs. Brasil, así:

«Desde luego, el desenvolvimiento del ser humano no queda sujeto a las iniciativas y cuidados del poder público. Bajo una perspectiva general, aquél posee, retiene y desarrolla, en términos más o menos amplios, la capacidad de conducir su vida, resolver sobre la

${ }^{29}$ Véase: Migliore, 2003, pág. 10

${ }^{30}$ Que luego retomó la Corte Suprema de Justicia de la Nación en el caso Arriola (Fallos: 332:1963 [2009]), volviendo en torno a la "autonomía personal" y el derecho a la privacidad previsto en el art. 19 de la Constitución argentina. En este fallo la Corte admitió que la tenencia de drogas para consumo personal estaba cubierta por la privacidad y que, por ello, no debía estar sujeta a sanción.

Ius Humani, v. 4 (2014/15), p. 32 
mejor forma de hacerlo, valerse de medios e instrumentos para este fin, seleccionados y utilizados con autonomía» (2006).

Esto que antecede, como habíamos indicado, se corresponde con una concepción en principio liberal, que sostiene que las sociedades no deben imponer ideales perfeccionistas. En ese contexto, las decisiones acerca de la moral privada corresponden solamente a los individuos, sin que esté permitido juzgar si ese plan es mejor o peor para la persona siempre que se refiera sólo a sí misma y siempre que no afecte derechos de otros (y, en sus casos, la moral pública).

En ese orden, se reconoce a las personas el derecho a desarrollar libremente su personalidad (lo que supone tanto un ámbito interno como un ámbito externo).

Tal derecho se encuentra reconocido - en nuestro casopor la Constitución de la República en el artículo 66 núm. 5, que reza:

Constitución, art. 66.- Se reconoce y garantiza a las personas: (...) 5. El derecho al libre desarrollo de la personalidad, sin más limitaciones que los derechos de los demás.

Este artículo recoge algo que hemos venido señalando constantemente. Y es que la única barrera a estos efectos son los derechos de terceros; en lo demás, cualquier injerencia es arbitraria y pretendidamente perfeccionista, lo que en modo alguno estaría justificado y, por el contrario, proscrito.

El derecho a desarrollar libremente la personalidad, consecuencia de la libertad y, luego, de la privacidad, relacionada en los casos específicos con la intimidad, está cubierta por la intangibilidad de las acciones privadas.

En este derecho al libre desarrollo de la personalidad o, llanamente, libre desarrollo personal, se enmarcan «asuntos tan heterogéneos como la posibilidad de contraer matrimonio, vivir en 
unión libre o permanecer soltero ${ }^{31}$, ser madre ${ }^{32}$, elegir el propio nombre ${ }^{33}$, escoger la opción sexual ${ }^{34}$, definir la apariencia o la clase de educación que se quiera tener ${ }^{35}$ o el procedimiento médico que se está dispuesto a aceptar cuando se está enfermo» (Bernal Pulido, 2008, pág. 250).

\section{LA LIBERTAD RELIGIOSA Y LA OBJECIÓN DE CONCIENCIA}

La libertad de conciencia supone hacerse de las propias convicciones, lo cual tiene una base en el libre pensamiento y en

${ }^{31}$ En el Ecuador estos derechos se encuentran reconocidos por los artículos 67 y 68 de la Constitución de la República, aunque también abordan otras cuestiones.

${ }^{32}$ En este caso, nuestra Constitución aborda este derecho en el artículo 66 núm. 10 , en otros habla sobre las responsabilidades de la maternidad (y de la paternidad), por ejemplo en los artículos 69 núms. 1, 4 y 5, 83 núm. 16 o 43 de la Constitución de la República.

${ }^{33}$ En el Ecuador este derecho se encuentra reconocido en el artículo 66 núm. 28 , además de que se reconocen ciertas facultades relacionadas con el derecho a la identidad más allá del propio nombre.

${ }^{34}$ En el Ecuador este derecho se encuentra protegido por el artículo 66 núm. 9 de la Constitución de la República.

35 Relacionado, de modo general, con el libre desarrollo de la personalidad, además está recogido por otros preceptos como el artículo 26 de la Constitución ecuatoriana. De modo genérico la educación se encuentra regulada y controlada por el Estado, de lo que infiere que incluso en los casos en que las instituciones educativas son "privadas" no existe propiamente una "educación privada", sino una "educación pública de gestión privada". Sostenemos, en este sentido, que debe respetarse incluso los casos en que la educación se aparte de los estándares de conocimiento a que aspira el Estado, además de que debería reconocerse la educación propiamente privada o el sistema de "auto-didacta". Además el Estado no debe alterar, por vía de imposición, el ideario de las instituciones educativas. De ese modo, es lo mismo irrazonable exigir determinada educación religiosa en un colegio laico, como determinada educación sexual (por dar un ejemplo) en un colegio católico. Entendemos que esto no riñe con el artículo 28 de la Constitución.

Ius Humani, v. 4 (2014/15), p. 34 
el libre desarrollo de la personalidad. No debe dejar de tenerse en cuenta que estos supuestos fundamentan lo que el artículo 66 núm. 11 de la Constitución ecuatoriana reconoce como:

Constitución, art. 11.- El derecho a guardar reserva sobre sus convicciones. Nadie podrá ser obligado a declarar sobre las mismas. En ningún caso se podrá exigir o utilizar sin autorización del titular o de sus legítimos representantes, la información personal o de terceros sobre sus creencias religiosas, filiación o pensamiento político; ni sobre datos referentes a su salud y vida sexual, salvo por necesidades de atención médica.

De otro lado, en unos de los aspectos centrales devenidos de la propia personalidad se encuentran las creencias individuales respecto de la visión religiosa de la vida. En efecto, la religión como misterio, como intuición humana de lo trascendente, se encuentra presente en todas las sociedades humanas conocidas. En ese marco, la libertad religiosa supone, por supuesto, poder acceder libremente a las creencias y prácticas religiosas que se estimen convenientes respecto de las propias visiones o, claro está, no adscribir a ninguna de ellas. En ese sentido, el derecho a la libertad religiosa se basa en las mismas consideraciones generalmente aplicables a los demás derechos, o sea la aceptación de que ciertas cualidades ontológicas, sobre todo la dignidad como principio y basamento de los derechos humanos, fundamentan la intangibilidad del individuo y su trascendencia respecto de la comunidad humana y de las prácticas colectivas. Nuevamente, el orden o moral pública, y los derechos de terceros, son la única limitante de la libertad religiosa también protegida por la privacidad.

Esto lo ha previsto la Constitución ecuatoriana en su artículo 66 núm. 8, que reconoce «el derecho a practicar, conservar, cambiar, profesar en público o en privado, su religión o sus creencias, y a difundir individual o colectivamente, con las restricciones que impone el respeto a los derechos». 
Cierta jurisprudencia ha reconocido la amplitud de estos ámbitos, señalando que el individuo tiene derecho a proteger esa esfera, incluso cuando una intromisión en ella pudiera considerarse "beneficiosa" para esa persona. Tal es el caso, por ejemplo, de las transfusiones sanguíneas que los creyentes del culto de los Testigos de Jehová suelen rehusarse a recibir. Esto fue tratado en la causa Bahamondez, donde la Corte Suprema de Justicia argentina dijo, sobre el artículo 19 de la Constitución Nacional $^{36}$, que reconoce en el derecho a la privacidad, lo siguiente:

«[El artículo 19] concede a todos los hombres una prerrogativa según la cual pueden disponer de sus actos, de su obrar, de su propio cuerpo, de su propia vida de cuanto les es propio. Ha ordenado la convivencia humana sobre la base de atribuir al individuo una esfera de señorío sujeta a su voluntad; y esta facultad de obrar válidamente libre de impedimentos conlleva la de reaccionar u oponerse a todo propósito, posibilidad o tentativa por enervar los límites de esa prerrogativa» (1993).

Similar cuestión ocurrió en la causa Albarracini Nieves, en la que la Corte confirmó su pronunciamiento, salvaguardando siempre la esfera intangible de la privacidad humana. En ese caso, la Corte sostuvo:

«[N]o resultaría constitucionalmente justificada una resolución judicial que autorizara a someter a una persona adulta a un tratamiento sanitario en contra de su voluntad, cuando la decisión del individuo hubiera sido dada con pleno discernimiento y no afectara directamente derechos de terceros. Así, mientras una persona no ofenda al orden, a la moral pública, o a los derechos ajenos, sus comportamientos incluso públicos pertenecen a su privacidad, y hay que respetarlos aunque a lo

\footnotetext{
${ }^{36}$ Constitución Nacional de Argentina, Art. 19.- Las acciones privadas de los hombres que de ningún modo ofendan al orden y a la moral pública, ni perjudiquen a un tercero, están sólo reservadas a Dios, y exentas de la autoridad de los magistrados. Ningún habitante de la Nación será obligado a hacer lo que no manda la ley, ni privado de lo que ella no prohíbe.
}

Ius Humani, v. 4 (2014/15), p. 36 
mejor resulten molestos para terceros o desentonen con pautas del obrar colectivo» (2012).

En ambos casos prevalecieron las creencias religiosas de los individuos, aun cuando argumentos aparentemente justificados de defensa de la vida pudieran oponérseles. No obstante, y como hemos venido señalando, la propia vida y su relación con la libertad amparan estas creencias, que no pueden ser sustituidas por visiones externas del bien porque entonces estarían violando también la dignidad humana de la persona como ser autónomo.

Conforme a lo descrito, la defensa de las propias creencias supone asimismo la potestad de no ser constreñido a realizar actos que las vulneren. De esto deviene la objeción de conciencia, que se deriva de un principio general del constitucionalismo en virtud del cual «nadie puede ser obligado por la ley a realizar algo que ofende su pensamiento y su voluntad, cuando tal omisión no se deriva en un daño para terceros» (Toller, 2007, pág. 11).

También esto lo ha reconocido la Constitución ecuatoriana en su artículo 66 núm. 12, donde consagra:

Constitución, art. 66, num. 12.- El derecho a la objeción de conciencia, que no podrá menoscabar otros derechos, ni causar daño a las personas o a la naturaleza. Toda persona tiene derecho a negarse a usar la violencia y a participar en el servicio militar.

La objeción de conciencia habilita para oponerse a realizar lo que ofende al propio pensamiento y, en último término, es esa misma la razón por la que los pueblos - ya colectivamenteposeen el derecho a revelarse contra la opresión. Por ejemplo, la Constitución ecuatoriana reconoce este derecho en el artículo 98 y en el artículo 416 núm. 8. Este derecho tiene, además, un raigambre en la Declaración Universal de los Derechos Humanos (1948), que en su preámbulo considera «esencial que los derechos humanos sean protegidos por un régimen de Derecho, a fin de que el hombre no se vea compelido al supremo recurso de la rebelión contra la tiranía y la opresión». Antes incluso, en el contexto de lo 
que nuestra rama conoce como la etapa clásica del constitucionalismo, la Declaración de Independencia de los Estados Unidos de América (1776) reconocía en su preámbulo el derecho a «reformar o abolir» las formas de gobierno que se volviesen destructoras de los principios en los que debía fundarse efectivamente el gobierno. Similar principio se encuentra presente al final del artículo 2 de la Declaración de los Derechos del Hombre y del Ciudadano (1789), donde reconoce el derecho a «la resistencia a la opresión».

\section{LAS ACCIONES PRIVADAS, LA INVIOLABILIDAD DE DOMICILIO Y DE CORRESPONDENCIA}

La privacidad humana alcanza particular importancia en el ámbito domiciliario. Justamente, muchas de las acciones íntimas o privadas se realizan en este entorno. Las injerencias arbitrarias en la privacidad son generalmente reprochables, pero además son particularmente invasivas si se perpetran en el domicilio donde una persona o familia residen.

En el ámbito ecuatoriano, el derecho a la inviolabilidad de domicilio se encuentra reconocido por la Constitución en su artículo 66 núm. 22, así:

Constitución, art. 66, num. 22.- El derecho a la inviolabilidad de domicilio. No se podrá ingresar en el domicilio de una persona, ni realizar inspecciones o registros sin su autorización o sin orden judicial, salvo delito flagrante, en los casos y forma que establezca la ley.

La inviolabilidad de correspondencia, por su parte, se encuentra recogida en el artículo 66 núm. 21, que prevé:

Constitución, art. 66, num. 21.- El derecho a la inviolabilidad y al secreto de la correspondencia física y virtual; ésta no podrá ser retenida, abierta ni examinada, excepto en los casos previstos en la ley, previa intervención judicial y con la obligación de guardar el secreto de los 
asuntos ajenos al hecho que motive su examen. Este derecho protege cualquier otro tipo o forma de comunicación.

Las disposiciones señaladas son claras en sus previsiones, de modo que en su virtud queda vedada toda intromisión ilegítima en el domicilio y en la correspondencia de los individuos. Mucha atención deben tener los jueces en no amparar intrusiones estatales ilegítimas.

Nos resta decir que, para el caso del domicilio, entendemos incluidos todos los lugares donde la persona resida y, asimismo, habitaciones de hoteles o similares en los que cierta privacidad analogable a la domiciliaria es exigida, siempre en los términos que el principio de razonabilidad consienta. A efectos de esta interpretación no debe olvidarse que la Constitución ecuatoriana recoge un principio básico del constitucionalismo contemporáneo, así en el artículo 11 núm. 5 que manda a aplicar la norma y la interpretación que más favorezca a la efectiva vigencia de los derechos constitucionales.

\section{LAS ACCIONES PRIVADAS DE LA ASOCIACIÓN HUMANA}

La privacidad generalmente asignada al individuo perdería sentido si además esas mismas aptitudes no pudieran extrapolarse, en tanto sea posible, a la asociación humana. De hecho, esa relación se ha reconocido por parte de la Corte Suprema de Justicia de los Estados Unidos en el ya mencionado caso Griswold vs. Connecticut. En esa oportunidad la Corte entendió:

«Varias garantías crean zonas de privacidad. El derecho de asociación contenido en la sombra de la Primera es uno [de ellos]» (1965).

Al respecto, el profesor Toller ha entendido que puede realizarse un trasvasamiento o proyección de los derechos 
individuales de las personas a las asociaciones o entidades que ellas conforman; en tanto que,

«[e]l hombre es un ser entitativamente social (...) Por eso los derechos y libertades constitucionales y fundamentales que poseen las personas individuales se transmiten a las entidades que ellas conforman cuando, ejerciendo el derecho a asociarse con fines útiles, se reúnen para realizar mediante esas personas jurídicas, tareas comprendidas dentro de aquellos derechos» (Toller, 2007, pág. 5).

Estos mismos razonamientos fueron usados en Board of Education vs. Barnette, donde la Corte Suprema estadounidense dijo:

«El derecho de "asociación” (...) es más que el derecho a asistir a una reunión; incluye el derecho a expresar las actitudes o filosofías propias por la membresía en un grupo o por la afiliación en él» $(1965)^{37}$.

Dentro de las formas asociativas, quizás la más importante - y la que mayores niveles de rigurosidad para evitar intromisiones arbitrarias merece- es la familia. El núcleo familiar (que la Constitución ecuatoriana reconoce en sus diversas formas en su artículo 67) es inviolable en cuanto a sus creencias y valores. En esa misma virtud, la familia posee el derecho a educar a los hijos, en particular los padres y representantes pueden escoger la educación que deseen darles. Tal cosa se ha reconocido en el artículo 29 inciso segundo de la Constitución ecuatoriana, que dice:

Constitución, art. 29, inc. $2^{\circ}$.- Las madres y padres o sus representantes tendrán la libertad de escoger para sus hijas e hijos una educación acorde con sus principios, creencias, y opciones pedagógicas.

Habrá que colegir, de todo lo que hemos venido señalando, que si la familia es una entidad privada entonces está también

37 Griswold vs. Connecticut, 381 U.S. 479 (1965) —con relación a Board of Education vs. Barnette, 319 U.S. 624-.

Ius Humani, v. 4 (2014/15), p. 40 
cubierta por la garantía de intangibilidad devenida de las previsiones constitucionales y, sobre todo, de una institución de derecho natural que reconoce una esfera de privacidad innegable.

En cuanto a esto, en Boyd vs. United States, la Corte Suprema estadounidense señaló:

«[Las Enmiendas, Cuarta y Quinta, protegen a las personas contra toda invasión gubernamental] de la santidad del hogar de un hombre y de las privacidades de la vida» (1886).

De allí también se ha inferido que la educación de los hijos ha sido asignada naturalmente a los padres, y que el Estado no puede reemplazarlos sin cometer una arbitrariedad manifiesta. Estas mismas consideraciones fueron realizadas en la causa Ramírez de la Corte Suprema de la Nación argentina, donde se dijo:

«Todo padre y madre tienen el derecho y el deber de velar por sus hijos menores no obstante los defectos que pueden tener y que son propios de la condición humana, si no han sido inhabilitados para el efecto. Desconocerlo podría introducir un gravísimo factor de perturbación tanto en lo moral como en lo social; y aun comportar un riesgo de que una eventual concepción utópica y totalitaria atribuyera al Estado la función que la propia naturaleza ha conferido a los padres» (1983).

Junto a estos argumentos, sumamos los que la Corte Suprema de los Estados Unidos realizó en los casos Pierce vs. Society of Sisters, Meyer vs. State of Nebraska y Winconsin vs. Yoder. Particularmente, en este último, donde se reconoció el derecho de los padres a educar a sus hijos manteniendo para sí sus creencias en materia religiosa, en este caso de las familias de la secta Amish. Allí se señaló:

«[P]arece claro que si el Estado, como parens patriae tiene el poder de 'salvar' al niño de sí mismo o de sus padres Amish, requiriéndoles dos años de educación secundaria formal, el Estado 
influirá, en gran medida, si es que no determinará, el futuro religioso del niño» $(1972)^{38}$.

Estas cuestiones traen implicaciones en diversos casos en los que una lógica puramente consecuencialista o utilitarista del Estado puede entrometerse en la privacidad humana.

En una de tantas cuestiones al respecto, se ha abordado también aquella del asesoramiento en materia sexual a menores. Sobre este tema los profesores Toller y De Reina Tartière han realizado un trabajo titulado: «Interés estatal y patria potestad en el asesoramiento a menores en materia sexual», en el que han expuesto en buena parte las razones por las que los padres retienen estas potestades.

Caso particular a este respecto es el que ha ocurrido en tiempos recientes en el Ecuador donde, con base en el Reglamento que regula el acceso y disponibilidad de métodos anticonceptivos en el Sistema Nacional de Salud, se puede acceder a la pastilla de anticoncepción de emergencia libremente desde los 12 años de edad sin que medie información o consentimiento paterno, materno o de tutor competente.

Esto no es aceptable en tanto que pretender que el Estado se haga cargo de modo general de la educación sexual de los menores de edad contraría ciertos derechos que las familias retienen como unidad y que son expresión también de la individualidad humana (pues supone el reconocimiento de la asociación como unidad). Junto a esto, los padres retienen el derecho a la patria potestad, no sólo como derecho civil, sino como derecho humano asignado por la misma naturaleza. Lo contrario apoyaría una consideración más bien colectivista donde la educación de los hijos de todos nos corresponde a todos. Eso sería en sí mismo un sinsentido. Excluir deliberadamente a los padres o tutores supone extirpar parte de sus derechos, lo que no puede aceptarse, inclusive por las previsiones del artículo 11 núm.

${ }^{38}$ De la traducción de Miller, Gelli \& Cayuso, 1991, pág. 760.

Ius Humani, v. 4 (2014/15), p. 42 
4 de la Constitución. También, como antes mencionamos en este trabajo, debe tenerse en cuenta que los derechos conviven en unidad y que la mejor interpretación debe armonizarlos y no sacrificar unos por otros (Maldonado Muñoz, 2013, págs. 11-16). No debe olvidarse que los mismos argumentos podrían servir para señalarnos determinada educación religiosa, moral o política por parte del Estado, y eso contrariaría los postulados aquí recogidos, favoreciendo ilegítimamente una moral determinada o una sociedad perfeccionista. Más aún, no está demostrado que exista, dentro de cierto rango, una educación que se entienda preferible a otra.

De otro lado (más allá del ámbito familiar), las demás asociaciones en general, siempre que persigan un fin lícito y determinado, y siempre que posean un ideario identificable, pueden negarse a realizar ciertas actividades que vayan en detrimento de las razones por las que han conformado la asociación.

No debe olvidarse que la libertad de pensar, que luego da justificación a la libertad de expresarse $y$, en ese mismo orden de cosas, se relaciona con la facultad de elegir la propia personalidad, hacen comprender que en muchos de los casos la asociación sea vocación de esas aptitudes y, como es de suponer, refleje también las creencias del grupo de personas que adscribe a esas ideas.

De ese modo, el profesor Toller ha hablado de un derecho a 'la objeción de conciencia de las instituciones', que es nada más que «la proyección de la objeción de conciencia personal de quienes fundaron y dirigen la persona jurídica» (Toller, 2007, pág. 11). Lo que nosotros entendemos se aplica también y naturalmente a sus miembros en general, puesto que se han sumado a la asociación porque se entiende que han encontrado en ella a sus pares ideológicos con relación a cierto aspecto de las creencias y valores humanos.

Esta objeción de conciencia institucional serviría, verbigracia, para que de modo general las instituciones de salud 
creadas al amparo de un ideario, por ejemplo, religioso - como es el caso de muchas instituciones - puedan oponerse a determinadas prácticas que conculcan sus creencias y que afectarían seriamente a las convicciones por las que hacen parte de la asociación. Esto puede resultar molesto para algunas personas que consideren conservadoras ciertas visiones. Lo cierto es que, sin embargo, eso es también propio de la privacidad y de la libertad humana. Además de que la misma lógica sirve para proteger otras opciones vitales que se pueden hacer molestas a visiones conservadoras. La privacidad, en ese ámbito, se refiere a la generalidad de las personas y ampara sus propias convicciones y creencias, cualquiera sean éstas mientras no afecten derechos legítimos de terceras personas.

\section{A MODO DE CONCLUSIÓN}

En el varias veces citado caso Griswold vs. Connecticut de la Corte Suprema de los Estados Unidos se señaló con acierto:

«Nosotros tratamos con un derecho a la privacidad más viejo que el Bill of Rights, más antiguo que nuestros partidos políticos, más viejo que nuestro sistema escolar» (1965).

Nosotros entendemos, precisamente, que esa es la razón por la que la esfera privada es intangible y que eso sirve en contra de todas las intromisiones, pero que trata de blindarse, sobre todo, de las estatales. La esfera que corresponde propiamente al individuo, a su familia o a las asociaciones de las que es parte, es sagrada. Nadie tiene derecho a violentarla o a desconocerla, menos aún el Estado. No debe olvidarse que, incluso históricamente, el individuo le precede. Esta última es la razón por la que el Estado constitucional o democrático ha mantenido incólume, dentro de sus principios, a este sector propiamente privado que sigue siendo, y deberá seguir siendo, intangible. La privacidad está sujeta solamente a las reglamentaciones razonables que no se internen en Ius Humani, v. 4 (2014/15), p. 44 
su contenido mismo, que resulta entonces indisponible y que siempre se debe proteger.

En ese sentido hemos hablado de la intangibilidad de las acciones privadas, entendiendo que es una garantía amplia, amparada —en el caso ecuatoriano- por el artículo 11 núm. 8 de la Constitución ecuatoriana y, además, reconocida por diversas normas constitucionales (aparte de las que contienen los instrumentos internacionales de derechos humanos).

Hemos procurado, entonces, delinear ciertos aspectos que la garantía de la que hablamos recoge y ampara. Esto tiene y seguirá teniendo relevancia en cuanto la esencia misma de los derechos fundamentales descansa en la naturaleza de la persona, en ciertas cualidades que hacen que inherentemente merezca ciertos derechos y prerrogativas; una de las más importantes en el contexto social, la más central para el individuo, es aquella que permite que el hombre busque realizarse y que, por sus propios medios, busque la felicidad y el objeto mismo de su existencia. 


\section{REFERENCIAS}

Alexy, R. (2003). La naturaleza de la filosofía del derecho. Revista DOXA: Cuadernos de Filosofía del Derecho, 26, págs. 146-159.

Barile, P. (1984). Diritti dell'uomo e libertà fondamentali. Bologna: Società editrici il Mulino.

Bernal Pulido, C. (2008). El derecho de los derechos. Colombia: Universidad Externado de Colombia.

Bidart Campos, G. (2008). Compendio de Derecho Constitucional. Buenos Aires: Ediar.

Bobbio, N. (1985). Liberalismo e democrazia. Milano: Franco Angeli.

Bobbio, N. (2009). Teoría General de la Política, $3^{\text {a }}$ edición. Madrid: Trotta.

Burgoa, I. (2009). Las garantías individuales. México: Porrúa.

Comanducci, P. (2002). Formas de (neo)constitucionalismo: un análisis metateórico. Isonomía, 16, págs. 90-112.

Corral Talciani, H. (2000). Configuración jurídica del derecho a la privacidad I: origen desarrollo y fundamentos. Revista chilena de derecho 27, 1, págs. 51-79.

Kennedy, A. M. (1-IX-1993). La Libertad de Expresión. (A. M. Kennedy, Intérprete). Encuentro entre Cortes de Estados Unidos y Argentina. Corte Suprema de Justicia Argentina, Buenos Aires, Argentina.

Maldonado Muñoz, M. (2012/2013). El principio de razonabilidad y su aplicación al estudio de validez de las normas jurídicas. Ius Humani, 3, págs. 139-174.

Massini Correas, C. I. La exigibilidad jurídica de las normas morales: iusnaturalismo, liberalismo y comunitarismo. El Derecho, t. 170, págs. 887-893.

Massini Correas, C. I. (1994). Filosofía del Derecho. El Derecho y los derechos humanos. Buenos Aires: Abeledo-Perrot.

Migliore, J. ((5-8)-XI-2003). Liberalismo y comunitarismo (los alcances de la racionalidad práctica). Trabajo presentado en el $6^{\circ}$ Congreso Nacional de Ciencia Política de la Sociedad Argentina de Análisis Político. Buenos Aires.

Miller, J. M., Gelli, M. A., \& Cayuso, S. (1991). Constitución y derechos humanos. Buenos Aires: Astrea.

Ius Humani, v. 4 (2014/15), p. 46 
Nino, C. S. (2005). Fundamentos de Derecho Constitucional. Buenos Aires: Astrea.

Pacheco Zerga, L. (2007). El "derecho de morir" y el "deber de matar" por respeto a la dignidad humana. Revista de Derecho Universidad de Piura 8, 8, págs. 45-60.

Rawls, J. (1996). Liberalismo político. México: Fondo de Cultura Económica.

Rawls, J. (2003). Teoría de la justicia. México: Fondo de Cultura Económica.

Rubenfeld, J. (II-1989). The right of privacy. Harvard Law Review 102, 4, págs. 737-807.

Taylor, C. (1993). El multiculturalismo y la política del reconocimiento. México: Fondo de Cultura Económica.

Toller, F. (2007). El derecho a la objeción de conciencia de las instituciones. Elementos generales y análisis de la situación de los centros de salud privados. Vida y Ética 8, 2. en prensa, págs. 20.

Toller, F., \& De Reina Tartiére, G. (1-VIII-2002 \& 2-VIII-2002). Interés estatal y patria potestad en el asesoramiento a menores en materia sexual. $E l$ Derecho, págs. $12-16$ \& págs. 1-3.

Warren, S. D., \& Bandreis, L. D. (XII-1890). The right of privacy. Harvard Law Review 4, págs. 193-220.

Zagrebelsky, G. (2011). El derecho dúctil. Ley, derechos, justicia, 10a edición. Madrid: Trotta.

Zanotti, G. (2006). Hacia un liberalismo clásico como la defensa de la libertad personal. Doxa, págs. 233-253.

\section{Jurisprudencia}

Albarracini Nieves s/ medidas precautorias, A523 XLVIII (C.S.J.N. 2012).

Bahamondez, Fallos 316:479 (C.S.J.N. 1993).

Bazterrica, Fallos 308:1032 (C.S.J.N 1986).

Boyd vs. United States, 116 U.S., 616 (U.S. Supreme Court 1886).

Corte Costituzionale, n. 121 (Corte Costituzionale 1963).

Corte Costituzionale, n. 366 (Corte Costituzionale 1991). 
Gramajo, Fallos 329:3680 (C.S.J.N. 2006).

Griswold vs. Connecticut, 381 U.S. 479 (U.S Supreme Court 1965).

Meyer vs. State of Nebraska, 262 U.S. 390, 399 (U.S. Supreme Court 1923).

Olmstead vs. United States, 277 U.S. 438 (U.S. Supreme Court 1928)

Opinión Consultiva 5/86, Corte IDH.

Pierce vs. Society of Sisters, 268 U.S. 510 (U.S Supreme Court 1925).

Ponzetti de Balbín c/ Editorial Atlántida, Fallos 306:1892 (C.S.J.N. 1984).

Ramírez, Fallos 305:1825 , Fallos 305: 1825 (C.S.J.N 1983).

Tristán Donoso vs. Panamá (Corte IDH enero 27, 2009).

Wisconsin vs. Yoder, 460 U.S. 390, 399 (U.S. Supreme Court 1923).

Wooley vs. Maynard, 430 U.S. 705 (U.S. Supreme Court 1977).

Ximenes Lopes vs. Brasil (Corte Corte Interamericana de Derechos Humanos, 4 de julio de 2006). 